\title{
Effect of drought stress on some morphological characteristics, quantity and quality of essential oil in Rosemary (Rosmarinus officinalis L.)
}

\author{
Reza Dehghani Bidgoli \\ Department of Watershed and Rangeland Management, University of Kashan, Iran.
}

Accepted 8 August, 2018

\begin{abstract}
In order to investigate the effect of different levels of drought stress on plant growth and essential oil composition of Rosemary aerial parts, a completely randomized design (CRD) with five treatments and three replications was conducted in the University of Kashan in 2017. The water stress treatments contained: 100 , $85,70,55$ and $40 \%$ of field capacity (FC). The results of statistical analysis showed that the water stress had significant effects on morphological characteristics and percentage and essential oil composition. By decreasing the amount of soil water, length, fresh weight of stem and fresh and dry weight of root reduced. Also, the percentage of essential oils first increased and then decreased. Decreasing of growth parameters was observed in the fifth level of stress (40\% of FC) and plants produced very little flowers. In order to investigate the essential oil factors, the aerial parts were separated and their essential oils were extracted, more essential oil was obtained in $85 \%$ FC condition. The important compound in the essential oils was Camphor which increased its value with increased level of drought stress. Also, Camphene, that has reduced the quality of the essential oil, first decreased by increasing the drought stress level and then increased. Therefore it can be concluded that in the initial levels of drought stress (85\% FC) the percentage of essential oil increased but with increasing drought stress (55\% FC), despite the decrease in the percentage of essential oil produced, its quality increased. So, the best stress level for increasing the essential oil production was $85 \%$ FC, and for the essential oil quality was $55 \%$ FC.
\end{abstract}

Keywords: Field capacity, essential oil, medicinal plant, drought, Rosmarinus officinalis L.

Email: dehghanir@kashanu.ac.ir. Tel: +98 3155913240.

\section{INTRODUCTION}

Rosmarinus officinalis L. (Rosemary) belongs to the family Labiatae or Lamiaceae is evergreen and woody plant and occurs as a shrub, under the shrub or herbaceous (Al-Sereiti et al., 1999). It is a dense aromatic plant with light green leaves and is a native of the Mediterranean region. The flowering tops and the Rosemary leaves mainly contain flavonoids, phenolic acids-especially rosmarinic acid (choleretic activities), and an essential oil (containing pinene, camphene, cineole, borneol, and camphor) to which it must have stimulatory effects (Oluwatuyi et al., 2004). Rosemary oils have been widely used for centuries as an ingredient in cosmetics, soaps, perfumes, deodorants, both for flavoring and preservation of food products (Arnold et al.,
1997) and they have also many therapeutic and help the distribution of drugs and antiseptics (Palevitch and Yaniv, 1991). Rosemary is used for treating different diseases in traditional medicine including depression, insomniac and arthritic pains (Zargari, 1995).

The diversity of the medicinal plants have the wild global significance and about 70,000 medicinal plant species at least has been used as a medicine once in the traditional herbal medicine. These plants are very rich in reservoirs of secondary metabolites that used as the active ingredients available for many medications (Zargari, 1995). Essential oils are the most important active ingredients in the plants, actually, essential oils are the remains of the main processes of plant metabolism, 
especially in the stress conditions (Aziz et al., 2008).

In the other hand, non-biological environmental stresses, especially salinity and drought stresses are considered the most important limiting production factors in agricultural systems, in addition to herbal properties, an important part of the annual yield of agricultural products is affected by environmental stress (Yang et al., 2009).

Accordingly, a large part of current and future studies and research programs focus on the two aspects of the improvement and development of medicinal herbs through increasing the amount of biomass and the content of pharmaceuticals, cultivation, and breeding through stimulation of biochemical cycles and finally regulation of various factors, including induction of environmental stress (Zargari, 1995; Azadbakht, 1999).

Drought stress is one of the main environmental and limiting factors on the distribution and production power of medicinal plants (Cakmakci et al., 2005). Researches on medicinal plants, especially under drought stress, are very separated, given the fact that a large part of the Iran country is facing limited water resources, more research is needed in this area. Many types of research have been conducted on the effects of drought stress on different medicinal plants of the Lamiaceae family. The results of these researches has shown that drought stress in some of this family species reduce the freshness and reduction of leaf area, for example, in drought stress condition, dry weight and plant height decrease compared to irrigation condition.

Therefore, dryness is one of the most important factors affecting the quantity and quality of plant productions such as essential oil. For example the amount of essential oil of Melissa officinalis decreases due to drought stress (Babalola, 2010). Based on results of Hosseinzadah et al. (2011), with increasing drought stress, plant height and number of lateral branches and essential oil yield of Calendula officinalis L. decreased, so that the highest plant height was obtained under the nonstress condition and maximum yield of essential oil was obtained under stress conditions of $3 \%$ filed capacity. Drought stress on peppermint showed that different treatments of drought have a significant role in all morphological traits and essential oil content and composition of essential oils of peppermint (Mahaian and Tuteja, 2005).

Considering the importance of this medicinal plant in the production of all types' cosmetic and pharmaceutical products and future water crisis, it is necessary to study the effect of drought stress on this medicinal plant. So the aim of this research is measuring growth characteristics and comparing yield and composition of essential oil of this species affected by different levels of drought stress.

\section{MATERIALS AND METHODS}

The experiment was conducted in 2017 at University of Kashan.
The study was based on completely randomized design (CRD) with 5 treatments and 3 replications that each replicate contained 5 pots. In each pot, 4 plants were planted with 5 leaves. Overall there were 75 pots in this experiment. The irrigation treatments used in this experiment were $\mathrm{D}_{1}=100 \% \mathrm{FC}, \mathrm{D}_{2}=85 \% \mathrm{FC}, \mathrm{D}_{3}=70 \% \mathrm{FC}, \mathrm{D}_{4}=$ $55 \% \mathrm{FC}$ and $\mathrm{D}_{5}=40 \% \mathrm{FC}$ (D - Drought treatment), each of these treatments were performed with three replications. The weighting method was used to apply drought stress treatments.

In this method, at first, a certain weight of the soil with loamysandy texture was poured into each pot. To determine the amount of moisture in the soil, 10 samples of the soil were prepared. Samples were dried at $100^{\circ} \mathrm{C}$ for $24 \mathrm{~h}$, after weighting, and the dry weight of each pot was determined, using the mean weight of the specimens, then a little water was poured to each pot to reach saturation (Kara and Baydar, 2013).

24 hours after complete irrigation of the pots, ten samples were dried again at an oven at $100^{\circ} \mathrm{C}$ for $24 \mathrm{~h}$ and the field capacity was determined. Based on the calculations, the weight of each pot for 5 treatments (field capacity as control and irrigation after drainage 40, 55, 70 and $85 \%$ water used to apply stress treatments) was calculated. During the growth period, the empty pots were weighed in each day and And when the weight of the pots did not change, it was considered as a treatment (Uhrikova et al., 1983).

Three months after vegetative growth, vegetative growth parameters such as root length, stem length, stem fresh weight, fresh and dry weight of roots were measured. Four months after and in the flowering stage, $100 \mathrm{~g}$ of samples were harvested for each treatment in order to apply the treatments. The essential oil was extracted by Clevenger (Distilled water method) and essential oil yield was calculated using total biomass.

\section{Plant material}

In each pot, 4 plants were planted with 5 leaves in August 2017 after 3 month samples were collected in November 2017 from cultivated. The aerial parts dried in the shade. A voucher specimen (No. KRBG548) of the plant was deposited in the herbarium of Kashan Research Botanical Garden, Kashan, Iran.

\section{Essential oils extraction}

Air-dried aerial parts were crushed separately in a grinder. Essential oils were obtained by hydrodistillation for $3.5 \mathrm{~h}$ using an all-glass Clevenger-type apparatus as recommended by European Pharmacopoeia (Anonymous, 1996). The oils were dried over anhydrous sodium sulfate and stored in the dark at low temperature $\left(4^{\circ} \mathrm{C}\right)$ until analysis.

\section{Preparation of methanol extracts}

Extracts of dried aerial parts of $R$. officinalis $L$ ( $80 \mathrm{~g}$ of each sample) were obtained by Soxhlet apparatus (Sokmen et al., 1999). The extracts were concentrated using rotary evaporator (Buchi, Flawil, Switzerland) at maximum temperature of $45^{\circ} \mathrm{C}$ and dried in vacuum oven $\left(45^{\circ} \mathrm{C}\right.$ overnight). Resulting samples were stored in suitable closed containers in refrigerator $\left(4^{\circ} \mathrm{C}\right)$ for further analysis. The yield of the dried extract from the leaves, flowers, and fruits were 45.9, 41.1 and $45.3 \%(w / w)$, respectively.

\section{Gas chromatographic analysis}

The essential oils were quantitatively analyzed using an Agilent HP6890 gas chromatograph (Agilent Technologies, Palo Alto, CA, USA) with HP-5MS $5 \%$ phenylmethylsiloxane capillary column 
(30 m $\times 0.25 \mathrm{~mm}$ i.d., $0.25 \mu \mathrm{m}$ film thickness; Restek, Bellefonte, PA) equipped with an FID detector. Oven temperature was programmed from 60 to $270^{\circ} \mathrm{C}$ at increment rate of $3^{\circ} \mathrm{C} / \mathrm{min}$. Injector and detector temperatures were set at 220 and $240^{\circ} \mathrm{C}$, respectively. Helium was used as carrier gas at flow rate of 1 $\mathrm{ml} / \mathrm{min}$, and diluted samples $(1 / 1000$ in $n$-pentane, $\mathrm{v} / \mathrm{v})$ of $1.0 \mu \mathrm{l}$ were injected manually and in the splitless mode. Percent composition of each component of the essential oils was computed from its peak area percent relative to respected spectrum total area (100\%).

\section{Gas chromatographic/mass spectrometric analysis}

Qualitative GC/MS analysis of the plant essential oils was performed on an Agilent HP-6890 gas chromatograph (Agilent Technologies, Palo Alto, CA, USA) with a HP-5MS 5\% phenylmethylsiloxane capillary column $(30 \mathrm{~m} \times 0.25 \mathrm{~mm}$ i.d., 0.25 $\mu \mathrm{m}$ film thickness; Restek, Bellefonte, PA) equipped with an Agilent HP-5973 mass selective detector (Agilent Technologies, Palo Alto, $\mathrm{CA}, \mathrm{USA}$ ) in the electron impact (Ionization energy: $70 \mathrm{eV}$ ) mode operating under the same condition as described above. Retention indices were calculated for all components using a homologous series of $n$-alkanes injected in conditions equal to samples ones. Identification of components of the essential oils was carried out based on retention indices $(\mathrm{Rl})$ relative to $n$-alkanes and computer matching with Wiley275.L and Wiley7n.L as well as comparisons of the fragmentation pattern of the mass spectra with data published in the literature (Adams, 2007). Identification of the spectra conducted by means of calculating the inhibition index and comparing it with the index in the reference books and papers, using the mass spectra of the standard compounds and the use of information in the library of the device.

\section{Statistical analysis}

Statistical analysis and analysis of variance were performed using SPSS statistical software. In order to check the significance of the difference, the values of the test were used ANOVA test at the 5\% confidence level and the comparison of the means was done using the LSD test.

\section{RESULTS}

Most of the traits were significantly influenced by the treatments (Table 1). With increasing drought stress, the fresh weight of stem first increased, and then decreased. Based on the results, the effect of drought stress on these two factors was significant. Also, with increasing drought stress, the fresh and dry weight of root significantly increased and then decreased (Table 1). Further, with increasing drought stress, stem length decreased significantly (Table 2) and (Figure 1). Also, with increasing drought stress, root length significantly increased, then decreased (Figure 1), and with increasing drought stress, the essential oil percentage decreased first, and then increased. The effect of drought stress on all these traits was significant.

In the context of the reduction of stem fresh weight, due to the effect of drought stress in $R$. officinalis L., this stress reduced the stem length, fresh weight, and number of seeds. Reducing fresh weight in aerial parts and reducing the amount of chlorophyll and the level of photosynthesis may be due to reduced plant energy, which is used to absorb water under stress conditions, increase protoplast concentration, change in respiratory tract pathways and phosphate-pentose pathway (Kara and Baydar, 2013). According to the results presented in table 3 the essential oils compounds of $R$. officinalis $L$ under different levels of drought stress were different, high percentage of essential oil obtained was in $D_{3}=$ (70\% FC), 99.5\%.

Table 1. Analysis of variance related to the effect of drought stress on morphological characteristics and quantity of Rosmarinus officinalis $L$ essential oil.

\begin{tabular}{lccccccc}
\hline sov & df & $\begin{array}{c}\text { Stem fresh } \\
\text { weight (g) }\end{array}$ & $\begin{array}{c}\text { Root fresh } \\
\text { weight (g) }\end{array}$ & $\begin{array}{c}\text { Root dry } \\
\text { weight } \mathbf{( g )}\end{array}$ & $\begin{array}{c}\text { Stem length } \\
\text { (cm) }\end{array}$ & $\begin{array}{c}\text { Root length } \\
\text { (cm) }\end{array}$ & $\begin{array}{c}\text { Essential oil } \\
\text { percentage }\end{array}$ \\
\hline Treatment & 4 & $40.66^{\star}$ & $58.33^{*}$ & $16.06^{\star}$ & $168.80^{\star}$ & $42.85^{\star}$ & $0.235^{\star *}$ \\
Error & 8 & 22.58 & 26.52 & 14.90 & 34.32 & 45.69 & 0.011 \\
CV\% & & 11.50 & 31.20 & 23.80 & 25.58 & 31.15 & 8.85 \\
\hline
\end{tabular}

* There are no significant differences between the numbers with the common alphabets in the LSD test at $1 \%$ level.

Table 2. Effect of drought stress on fresh weight root and stem of Rosmarinus officinalis $\mathrm{L}$

\begin{tabular}{cccc}
\hline Field capacity (\%) & Stem fresh weight (g) & Root fresh weight (g) & Root dry weight (g) \\
\hline 100 & $30.40 \pm 2.11^{\mathrm{b}}$ & $34 \pm 0.018^{\mathrm{b}}$ & $19.15 \pm 0.006^{\mathrm{c}}$ \\
85 & $35 \pm 3.12^{\mathrm{a}}$ & $42.85 \pm 0.32^{\mathrm{a}}$ & $25.05 \pm 0.009^{\mathrm{b}}$ \\
70 & $35 \pm 2.1^{\mathrm{a}}$ & $42 \pm 0.52^{\mathrm{a}}$ & $28.42 \pm 0.003^{\mathrm{a}}$ \\
55 & $39 \pm 2^{\mathrm{ab}}$ & $35.72 \pm 0.72^{\mathrm{ab}}$ & $25.40 \pm 0.001^{\mathrm{b}}$ \\
40 & $34.75 \pm 1.63^{\mathrm{b}}$ & $33.45 \pm 0.065^{\mathrm{b}}$ & $25 \pm 0.003^{\mathrm{b}}$ \\
\hline
\end{tabular}

Between averages with common alphabets, there is no significant difference statistically. 


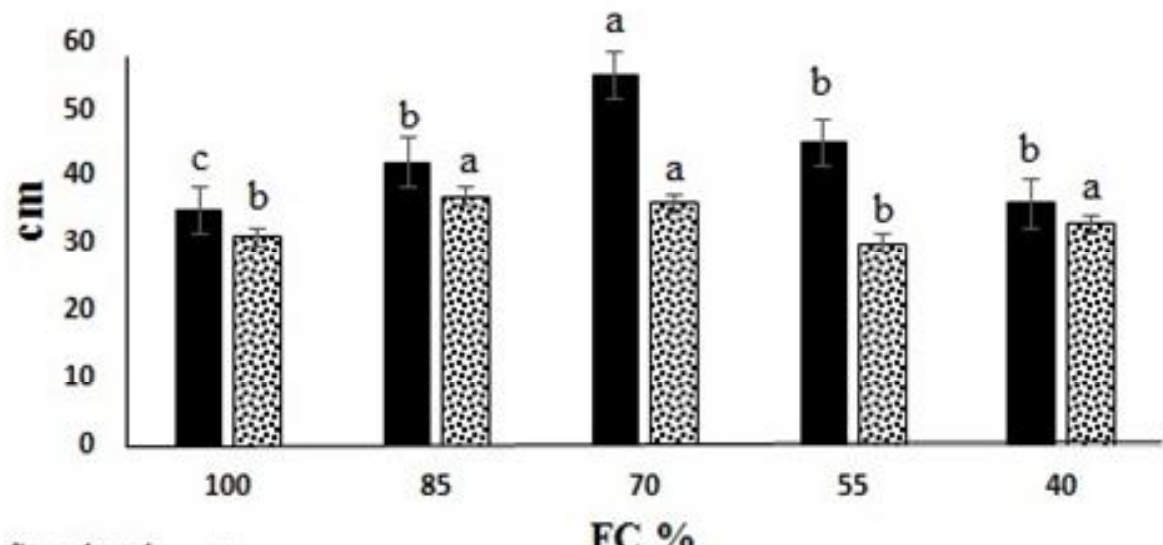

Stem lengh
Root length

FC $\%$

Figure 1. Effect of drought stress on stem and root length of Rosmarinus officinalis $\mathrm{L}$.

Table 3. Essential oils compounds of Rosmarinus officinalis L. under different levels of drought stress.

\begin{tabular}{|c|c|c|c|c|c|}
\hline \multirow{2}{*}{ Essential oil compound } & \multicolumn{5}{|c|}{ FC (\%) } \\
\hline & 100 & 85 & 70 & 55 & 40 \\
\hline Camphor & 38.82 & 42.73 & 41.9 & 43.96 & 47 \\
\hline alpha-thujene & 20.03 & 16.6 & 17.8 & 20.93 & 20.05 \\
\hline alpha-pinene & 6.03 & 14.56 & 11.75 & 6.46 & 2.22 \\
\hline 6-methyl-5-octene-2-one & 0.36 & 2.66 & 0.1 & 0.43 & 0.3 \\
\hline Camphene & 3.43 & 2.9 & 2.7 & 2.66 & 5.5 \\
\hline Sabinene & 1.26 & 0.83 & 0.16 & 0.33 & 0.13 \\
\hline beta-pinene & 0.66 & 0.43 & 0.1 & 0.16 & 0.16 \\
\hline Myrcene & 6.73 & 4.63 & 7.93 & 6.26 & 5.15 \\
\hline alpha-phelandrene & 3.9 & 2.46 & 3.2 & 3.73 & 3.7 \\
\hline alpha-terpinene & 6.03 & 4.06 & 4.1 & 5.3 & 4.9 \\
\hline Tricyclene & 1.76 & 1.03 & 2.05 & 2.03 & 1.72 \\
\hline 4-methy-4-vinylbutyrolactone & 1.13 & 0.73 & 1.16 & 1.3 & 1.05 \\
\hline p-cymene & 0.3 & 0.13 & 0.6 & 0.23 & 0.16 \\
\hline 1,8 cineol & 0.16 & 0.6 & - & 0.13 & 0.1 \\
\hline lialic alchol & 0.4 & 0.46 & 0.16 & 0.33 & 0.25 \\
\hline gama-terpinene & 0.23 & 0.3 & 0.15 & 0.46 & 0.15 \\
\hline cis-sabinene hydrate & 0.2 & 0.13 & - & 0.06 & 0.15 \\
\hline Verbenol & 0.06 & 0.86 & 0.75 & 1.3 & 1.13 \\
\hline Linalool & 0.33 & 0.2 & 0.1 & 0.2 & 0.1 \\
\hline trans-sabinene hydrate & - & 0.1 & 0.05 & 0.06 & 0.05 \\
\hline beta-thujone & 0.5 & 0.33 & 0.35 & 0.5 & 0.6 \\
\hline Cis-p-menth-2-en-1-ol & 0.6 & 2.16 & 0.2 & 0.33 & 0.5 \\
\hline 1-terpineol & 0.3 & 0.33 & 0.55 & 0.5 & 0.3 \\
\hline Borneol & 0.25 & 0.41 & 0.04 & 0.21 & - \\
\hline Total & 99.5 & 96.5 & 99.5 & 98.8 & 89.9 \\
\hline
\end{tabular}

\section{DISCUSSION AND CONCLUSION}

The results of this research is confirmed with research conducted on Achilla millefolium that effect of 2, 4, 6, 8 and 10-day irrigation periods and were investigated and in them with increasing drought stress the length of the stem decreased, and it was determined that with decreasing irrigation periods up to 10 days, the height 
and number of shoots and flowers, the diameter of flowers and the fresh and dry weight of flowers and the essential oil percentage of the plant decreased (Zahir et al. 2008). Also, in Thymus vulgaris, under the influence of drought stress and irrigation in 10-day irrigation periods, plant height, the dry and fresh weight of the plant are reduced compared with fewer irrigation periods or without stress (Patten and Glick, 2002).

One of the first signs of water scarcity is the reduction of turgor pressure and, consequently, cell growth and development, especially in stems and leaves, by limiting the growth of the cell. Also, the size of the limb is limited, which is the first significant effect of dehydration on the plants can be distinguished from their smaller size of leaves or height. Additionally, in dehydration, the absorption of water and food is also reduced, and thus the growth and development of leaves are limited.

In the context of increasing the root length under the increased drought stress, it is stated that the in the plants, in the face of drought stress, the root is one of the organs that begins to expand to increase the absorbent level of the plant (Tonutti and Liddle, 2010).

The expansion of root length increases the absorption capacity of water and decreases the drought stress effects. The results of this study are consistent with the results of research on two Mentha and Melissa herbs that had been conducted by (Razmjoo et al., 2008) and (Haig et al., 2009).

The results of increase in essential oil percentage at medium levels of drought stress were consistent with the results of Hassanpouraghdam et al. (2011), which the cut of irrigation at different stages of plant growth increased the percentage of essential oil of Lavandula officinalis Chaix and also with the results of study of Kara and Baydar (2013) that indicated, with increasing drought stress, the essential oil content of Lavandula sp. in $70 \%$ of the field capacity was added.

The increase of essential oil content in this treatment was $21.3 \%$ compared to control treatment. The important thing about this issue is, always with increases the level of stress levels we should not expect increase the amount of essential oil in the plants, because in more intense stress the plant uses more photosynthetic materials to make osmotic regulators and make carbohydrate compounds to provide the necessary conditions for survival.

According to the results, the essential oil components have changed under the influence of drought stress and with increase of drought stress, the amount of Camphor increased, 1,8cineol and alpha-terpinene decreased, and alpha-thujene, Camphene, and Myrcene first decreased in $85 \%$ and $70 \%$ drought stress level and then increased. It is worth noting that some essential oil components have not been produced at some levels of drought stress, especially at medium levels. With increasing drought stress to medium levels, the components of the essential oil that determine their quality have increased and so, decreased in favor of increasing the quality of the essential oil. Thus, Camphor, alpha-pinene and Sabinene, which are the most important compounds in this plant's essential oil, have been increased, and Camphene that has the reduction of essential oil quality, decreased.

Also, the changes in the composition of essential oil under drought stress have been reported in the other medicinal plants ., for example with increasing drought stress, dry weight and fresh weight of two species of Ocimum sp. affected by drought stress and decreased (Khalid, 2006). Also, research on the effect of drought stress on flower yield and flavanol content of Melissa officinalis $\mathrm{L}$. showed that the amount of these compounds decreases due to drought stress (Ozturk et al., 2004).

These changes can be due to using the more energy in the plant and a change in the respiratory tract that disrupts the production of essential oil enzymes and as a result lead to changes the essential oil components. Regarding the relatively good tolerance of Rosemary plants, it is possible to have extensive cropping in different regions with low irrigation and in warm seasons. Also, the increase in the percentage and quality of the essential oil may compensate for the reduction in yield due to stress. Therefore, the best level of stress is to increase the essential oil content of $85 \%$ of the field capacity and to increase the quality of essential oil is $55 \%$ of the field capacity.

\section{REFERENCES}

Adams RP, 2007. Identification of Essential Oil Components by Gas Chromatography/Mass Spectrometry: Allured Publishing Corporation. 350p.

Al-Sereiti MR, Abu-Amer KM, Sen P, 1999. Pharmacology of rosemary (Rosmarinus officinalis Linn.) and its therapeutic potentials. Indian $\mathrm{J}$ Exp Biol, 37(2): 124-130.

Anonymous, 1996. European Pharmacopoeia: Council of Europe $225 \mathrm{p}$.

Arnold N, Valentini G, Bellomaria B, Hocine L, 1997. Comparative study of the essential oils from Rosmarinus eriocalyx Jordan \& Fourr. From Algeria and Rosmarinus officinalis L. from other countries. J Essential Oil Res, 9(2): 167-175.

Azadbakht M, 1999. Classification of Medicinal Plants. Tabib Press Iran. $258-264$ pp.

Aziz EA, Hendawi ST, Azza EED, Omer EA, 2008. Effect of soil type and irrigation intervals on plant growth, essential oil and constituents of Thymus vulgaris. American-Eurasian J Agric Env, 5(3): 150-166.

Babalola OO, 2010. Beneficial bacteria of agricultural importance. Bio Lett, 32: 1559-1570.

Cakmakci R, Donmez D, Aydýn A, Sahin F, 2005. Growth promotion of plants by plant growth-promoting rhizobacteria under greenhouse and two different field soil conditions. J Soil Biol Biochem, 38: 14821487.

Haig TJ, Haig TJ, Seal AN, Pratley JE and Wu H, 2009. Lavender as a source of novel plant compounds for the development of a natural herbicide. J Chem Ecol, 35: 1129-1136.

Hassanpouraghdam MB, Hassani A, Vojodi L, HajisamadiAsI B, Rostami A, 2011. Essential oil constituents of Lavandula officinalis Chaix. from northwest Iran. Chemija, 22(3): 167-171.

Hosseinzadah F, Satei A, Ramezanpour MR, 2011. Effects of mycorrhiza and plant growth promoting rhizobacteria on growth, nutrient uptake and physiological characteristics in Calendula 
officinalis L. Middle East J Sci Res, 8(5): 947-953.

Kara N, Baydar H, 2013. Determination of lavender and lavandin cultivares (Lavandula sp.) containing high quality essential oil in Sparta, Turkey. Turk J Field Crops, 18(1): 58-65.

Khalid KA, 2006. Influence of water stress on growth, essential oil, and chemical composition of herbs (Ocimum sp.). Int Agron, 20: 289-296.

Mahaian S, Tuteja N, 2005. Cold, salinity and drought stresses: an overview. J Arch Biochem Biophy, 444: 139-158.

Oluwatuyi M, Kaatz GW, Gibbons S, 2004. Antibacterial and resistance modifying activity of Rosmarinus officinalis. J Phytochem, 65(24): 3249-3254.

Ozturk A, Unlukara A, Ipek A, Gurbuz B, 2004. Effects of salt stress and water deficit on plant growth and essential oil content of Lemon Balm (Melissa officialis L.). Pak J Bot, 36(4): 787-792.

Palevitch PD, Yaniv ZM, 1991. Medicinal plants of Holy land. Tel-Aviv, Tammuz Publisher Ltd, 1, 2-4.

Patten CL, Glick BR, 2002. Role of Pseudomonas putida in doleacetic acid in development of the host plant root system. Appl $\mathrm{J}$ Environ Microbiol, 68: 3795-3801.

Razmjoo K, Heydarizadeh P, Sabzalian MR, 2008. Effect of salinity and drought stresses on growth parameters and essential oil content of Matricaria chamomila. Int J Agric Bio, 4(4):443-450.

Sokmen A, Jones BM, Erturk M. 1999. The in vitro antibacterial activity of Turkish medicinal plants. J Ethnopharmacol, 67: 79-86.

Tonutti I, Liddle P, 2010. Aromatic plants in alcoholic beverages. J Flavour Fragrance, 25: 341-350.

Uhrikova A, Ferakova V, Schwarzova T, 1983. In IOPB chromosome number reports. Taxon, 32: 507-508.

Yang J, Kloepper JW, Ryu CM, 2009. Rhizosphere bacteria help plants tolerate abiotic stress. J Trends Plant Sci, 14(1): 1-4.

Zahir ZA, Munir A, Asghar HN, Shaharoona B, Arshad M, 2008. Effectiveness of rhizobacteria containing ACC deaminase for growth promotion of peas (Pisum sativum) under drought conditions. J Mic Biotech. 18: 958-963.

Zargari A, 1995. Medical Plants. 5th Edition, Tehran University Press.
Citation: Bidgoli RD, 2018. Effect of drought stress on some morphological characteristics, quantity and quality of essential oil in Rosemary (Rosmarinus officinalis L.). Adv Med Plant Res, 6(3): 4045. 